\title{
Governing the UK Contribution to Health Security: in Our National Interest?
}

Emily McMullen ( $\sim$ emilyjanemcmullen@gmail.com )

King's College London

\section{Research}

Keywords: Global Health Security, Health Security, Global Health Diplomacy, COVID-19, Governance

Posted Date: September 28th, 2020

DOl: https://doi.org/10.21203/rs.3.rs-83030/v1

License: (1) This work is licensed under a Creative Commons Attribution 4.0 International License. Read Full License 


\section{Abstract}

Introduction

Recent shifts in the UK international development and foreign policy landscape have revealed a broader scope for global health security activity across UK funding and policy priorities. A lack of clarity surrounding the governance architecture for the expanding UK health security community has led to a risk of fragmentation within the health, development and foreign policy communities. The study aimed to explore the contemporary governance capacity around the UK health security community through the accounts of its leaders and decision makers.

Methods

A qualitative research study was undertaken in the form of once off, semi-structured, in depth interviews with 12 key informants. Interviews were audio recorded and transcribed. Thematic analysis was used to code the data into themes. These coded transcripts and observations were supported by a review of contemporary literature and policy documentation in order to form a narrative of findings and draw conclusions.

Results

UK global health leaders and decision makers considered the governance architecture of the expanding UK health security community to be of insufficient capacity. The need for stronger governance is essential to make a compelling case for the ongoing political commitment and resourcing of the UK contribution to global health security, and its impact on wider UK global health efforts.

Conclusion

Findings from this study point to three strategic priorities required in order to strengthen the governance around the UK health security community: 1 ) Consensus needs to be built around a compelling public narrative for the UK contribution to global health security, 2) an effective model of coordination needs to be built for stakeholders active in the domain and, 3) forums for cross sector engagement and regulation must be created in order to find innovative solutions to these problems that extend beyond the boundaries of a single organisation or community.

\section{Background}

Global health is now at the vanguard of an era dominated by issues of national and global security ${ }^{1-3}$. Threats to health are no longer confined to global public health security targets or the protection from the threat of infectious disease transmission, ${ }^{4-6}$ but increasingly include a diverse range of actors and organisations promoting the role of health security as a means to human security ${ }^{7-10}$, and more recently to national security ${ }^{11-15}$.

Box 1 on appendix: Definitions used by study for Global Health, Global Health Diplomacy and Global Health Governance

Box 2 on appendix: Contested definitions: Health Security, Global Public Health Security, Human Security, Health and Security (Health as National Security), and Health Systems Security.

Although there is no consensus of an agreed definition of global health security, it is widely considered an important tool for making connections to improve the collective and individual health, security, and development of populations (Box 1 and 2 on appendix) ${ }^{15-17}$. This has been attributed to the recognition that global health security activity may not only ensure improved health outcomes but may enhance international relationships by managing shared vulnerability and by helping fragile states achieve stability, resilience, and influence ${ }^{12,18-20}$. Recent shifts in the UK international development and foreign policy funding landscape have seen an increasing scope and breadth of what is considered to constitute health security activity across the health and development communities. The COVID-19 pandemic is also rapidly evolving this area ${ }^{3,21-22}$. This has led to the global health, development and security communities intersecting with greater frequency ${ }^{23}$. The UK National Security Council (NSC) has taken a central role in crystalizing this broader interpretation of the remit of health security through i) the development of shared cross sector policy priorities of 'strengthening global security' and 'resilience and response to crisis' ${ }^{2}$, ii) the creation of an amalgamated department between the Department for International Development (DFID) and the Foreign and Commonwealth Office (FCO) ${ }^{24}$, and iii) the creation of the Joint Biosecurity Centre (JBC), using the Joint Terrorist Analysis Centre (JTAC) as a model ${ }^{25}$. The UK Government's successful petitioning in 2016 of the Organisation for Economic Co-operation and Development (OECD) to modernise the definition and parameters of Official Development Assistance (ODA), allowed for an increased focus on trade and security as a lens for global health and development spending ${ }^{26}$. By 2018 the UK's Fusion Doctrine ${ }^{2}$ and Biosecurity Strategy ${ }^{27}$ had further diversified the portfolio of activity promoted as part of the UK global health security preparedness and response, for example military to military defence medical co-operation with Pakistan. In 2019 the All-Party Parliamentary Group (APPG) for Biosecurity were set to review the UK contribution to the global health security agenda within the context of the imminent departure from the European Union. However, election purdah followed closely by the COVID-19 pandemic meant this process was never completed ${ }^{28}$. The pandemic has also driven substantial machinery of government changes that has seen in August 2020 the replacement of the UK Public Health England by the new National Institution for Health Protection (NIHP). Ostensibly NIHP is tasked to bring together JBC, NHS Test and Trace and public health under a single command structure to focus on health protection and security ${ }^{29}$.

With the expansion of global health security as a focus for policy cohesion and an increased diversity of engaged stakeholders, has come a growing interest in the opportunities for programme synergy to strengthen the UK contribution to global health security and of the impact on wider UK global health diplomacy 30-32. However, in practice, a lack of clarity surrounding the governance architecture for the expanding UK health security community has led to a risk of

Page 2/11 
fragmentation, as departments directly compete for attention and resourcing in response to a redefined scope and the pressure of a narrower array of funding. This not only has ramifications for operational activity, as recognised in the Exercise Cygnus recommendations ${ }^{33}$, but has the potential to undermine the UK's influence overseas at a time of post- COVID-19 pandemic socio-political uncertainty ${ }^{3}$.

In this pre-COVID-19 pandemic study we aimed to explore the contemporary governance capacity around the UK health security community. The unique access to high profile global health leaders and decision makers allowed for the exploration of distinct insights which set the current pandemic response in context. Due to the position of the participants and the timing of this study, the insights gathered from this study provide invaluable, unalloyed perspectives for the rapidly evolving policy environment around global health security.

\section{Methods}

\section{Study Design and Methodology}

A qualitative research study was undertaken in the form of semi structured in-depth interviews with key leaders and decision makers across the UK global health security community (list in Table 1 on appendix). The research approach was primarily inductive, building explanations from the data collected during the participant interviews ${ }^{34-35}$. This study design was chosen to capture the insight of experts who have viewed the development of the health security narrative and the history and practice of global health through years of experience, practice and expertise ${ }^{35-36}$. The values, position, and experience of the participants were considered in a constructivist approach to be part of the richness of the data. This was reflected in the study sampling and data analysis plan. A semi-structured interview guide (e-Appendix 1) was used to explore the participant's experience of the development of the UK narrative around global health security, the actors and architecture of the space. Questions were also asked regarding the political and diplomatic context, and potential opportunities and challenges for the governance of UK global health security activity. The work was underpinned by a comprehensive review of the relevant contemporary literature and UK policy documents.

\section{Sample Size and Strategy}

Interview participants were identified and recruited by non-probability purposive sampling of UK based leaders and decision-makers active in the global health security community. Each participant was considered for their personal and professional profile, networks and publications. To be eligible, participants were determined to be in a position of senior leadership in the field of global health, development, or foreign policy, and currently leading an aspect of the UK contribution to global health security. As national level decision makers, there was an explicit desire to use the data to inform potential change and reform by engaging, creating a dialogue and exploring responses with participants who had influence in this space. Particular focus was given to recruiting experts that

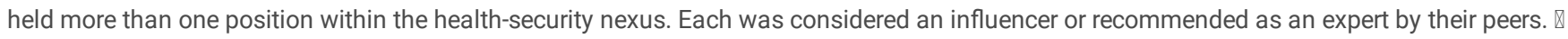

\section{Data Collection and Management}

Data collection took place between February and July 2017. An initial introductory email was sent inviting the participants to take part in the study. If agreement was received, then a follow up email was sent that included the participant information sheet and a written explanation of the consent process, with options for anonymity. Interviews were then scheduled at a convenient location and time determined by the participants. All but one participant chose to be interviewed in their own office space. Consent was obtained in person prior to the interview with a signed consent form. Interviews were audio recorded and transcribed verbatim into Microsoft Word within 72 hours and uploaded to Nvivo for Mac within one week. Transcriptions, policy documents, and additional observations were uploaded for coding and analysis onto a password protected laptop. Any learning points or feedback from the interview were recorded as memos for reflection and to highlight specific considerations for each interview's data. The interviews continued until a point of saturation was reached in responses in line with best practice ${ }^{37}$.

\section{Data Analysis}

A qualitative thematic analysis was performed using a mixed coding approach to establish themes for interpretation and discussion ${ }^{38-39}$. Transcriptions of the interviews were uploaded and coded according to standard methods for credibility and transparency to identify and compare excerpts from the data. Initial familiarisation with the data was undertaken, with data then classified and compared to create initial codes. Codes were then grouped into themes and subthemes and reviewed to ensure accurate reflection of the extracts and the broader data set. Triangulation and verification were undertaken with a review of contemporary literature and policy documentation in order to form a narrative of findings and draw conclusions. The final themes were refined and given definitions and labels to encompass the findings. Descriptive statistical analysis was applied to the data to detail the frequencies and levels of agreement for each statement. A threshold of $>10$ participant agreement for each theme was established to ensure significance. Findings were reviewed and presented in the form of tables and figures.

\section{Ethical Consideration}

A low risk ethics application was approved by the Kings College London Ethics Review (14 ${ }^{\text {th }}$ February 2017, reference number; LRU-16/17-2285) in line with the principles embodied in the Declaration of Helsinki. Interviews were numerically identified and transcribed into Microsoft Word documents with no identifiable data. The electronic copies were stored in a secure file on a password protected laptop. Participant anonymity and confidentiality were protected throughout the process.

\section{Results}


Twelve interviews (women $n=2$, men $n=10$ ) were secured and completed: a response rate of $100 \%$. The primary institutional affiliation and professional background of participants were collected for consideration as part of the analysis (Table 1 on appendix).

\section{Table 1 on appendix: Interview participant's affiliation and profession}

From the general thematic analysis three distinct main themes and four sub-themes of equal weighting emerged from the data: 1) The absence of a compelling narrative for the UK community operating in the health security nexus; a lack of common language and limited cross sector collaboration has led to concerns amongst participants regarding UK resource prioritisation and allocation, 2) Confusion as to the current architecture of UK governance around the expanding global health security agenda; no clear overarching policy or strategic leadership was noted, and 3) The role of global health security in wider UK health diplomacy.

\section{Theme 1: The absence of a compelling narrative for the UK community operating in the health security nexus}

\section{Lack of a common language}

When considering the scope of health security, most participants $(n=10)$ drew on the definition of global public health security established by the 2007 World Health Report ${ }^{4}$, additionally highlighting the complexity of managing the relationship between human security and health ( $\left.n=5\right)$, and the role of health security as part of a systems strengthening approach $(n=10)$. However, several of the participants $(n=10)$ also emphasized a recent broadening representation of health security in the UK policy and practice landscape due to a resurgence in popularity amongst policy-makers for the normative 'Health as a Bridge to Peace' (HBP) narrative, and an increased focus on investment in fragile and conflict affected states. While many of the programmes of work discussed traversed the intersections between these spaces (Figure 1 on appendix, e-Appendix 2), participants mostly defined health security activities and actors in line with the ideology and mandate of the organization that they were primarily affiliated with (Table 1 on appendix).

Figure 1 on appendix: Intersections of programmes considered UK global health security activities by key Informants pre Covid-19.

\section{e-Appendix 2: Activities considered by key informants to be part of global health security agenda pre Covid-19.}

Participants were divided as to the potential value of framing threats to health within the wider security narrative in order to broaden the discussion. Both in terms of practical response, and as a frame for creating a higher profile political debate.

"Almost always, security is a highly political ambition and so... more likely

to lead to the discussions about making sure the resources are available."

Interview 6

Recognition existed that the use of security as a lens for health activity had expanded the opportunity for engagement with a broader range of institutions and funding bodies $(n=6)$. Particular focus existed around activity intersections (Figure 1 on appendix) such as migration, conflict, or the response to resource scarcity affecting the capacity of countries to deal with disease. Yet caution was expressed by participants of; moving the debate away from its place within the UK's wider global commitments to Universal Health Coverage (UHC) and the Sustainable Development Goals (SDGs), of the risk of securitizing resources, and of reducing health to a strategic tool for foreign policy irrespective of health outcomes $(n=7)$.

Ultimately the development of a public position across UK communities engaged in health security activity was considered essential by all participants in order to coordinate decision making, programmes of work, and to justify resource use, both within the community and to the wider British public.

\section{Limited cross sector collaboration}

Domestic collaboration was seen as the biggest barrier to progressing the UK national and global health security agenda. As one participant noted:

We are terribly uncoordinated... at the moment I don't think there is an overarching view on this (global health security activity) ...we need a collective knocking of heads together to have a conversation!"

Interview 4

The broadening of the terminology around ODA, combined with increased competition for resources was reported by many to have dis-incentivised collaboration between institutions bidding for narrower caches of resources. Furthermore, a perceived politicization of aid and a reported disconnect between policy makers and the people implementing them was cited as 'creating a turf war over resources'. A tacit understanding was indicated that the institutions and departments involved in this agenda often still worked 'as silos' and in 'stove pipe'fashion. Participants described the need for improved transparency in multi-agency collaboration:

"We need to think collectively about how the UK operates internationally and how we draw upon our collective resources to achieve the biggest impact."

Interview 7 
Pockets of excellent cross-departmental collaboration for global health security were reported in the form of Zoonosis, Antimicrobial Resistance (AMR) and the UK's bilateral health alliances. In these projects, clear leadership and strategy meant that a collaboration across domestic organisations had enabled not only good joint working relationships at an operational level but facilitated informal connections and conversations around broader perspectives. These informal connections were reportedly further strengthened by a bridging of communities through intentional appointments of decision-makers into shared posts, secondments and cross institutional responsibilities (Table 1 on appendix). All participants had worked across more than one sector and this was reflected in a breadth of understanding of other sectors roles and values (e-Appendix 2). However, a knowledge of how the system should work was not often translated into a reality of practical collaboration, as reflected by one organisational leader:

"It is very easy to talk about cross-Whitehall collaboration but unless there is a project that does require our collective expertise then we just don't tend to work together."

Interview 7

Moreover, institutional incentive structures were considered to be about institutional growth as defined by Ministries. Where success had been achieved, participants reflected that an intentionality to find areas of overlap and team up for common purpose had existed. Operational collaboration by the increasingly diverse global health, and humanitarian communities responding to global health security emergencies, such as the West African Ebola outbreak, was reported to have facilitated a steep learning curve. Whilst participants recognised the need to work collectively to response to global threats, the complex, and at times controversial, challenges of multi-agency participation in terms of; programme duplication, the use of non-traditional health providers such as the security sector, and the blurring of institutional boundaries had increased awareness in the need for synergy across health security activity.

\section{Theme 2: Confusion as to the current architecture of UK governance around the health security agenda}

\section{Unclear Community Leadership}

Participants reported the National Security Council (NSC) at the Cabinet Office to be

the nominal leadership of the health security agenda for the UK. However, only two of the senior decision makers currently reported direct engagement with the NSC and three further could testify to historical engagement with the Cabinet Office. Participants expressed frustration at a lack of named individuals for engagement and accountability, confirming that in the last few years there had been significant changes across government resulting in a significant loss of institutional memory and relationships:

"I couldn't name an institution or person who is leading this from the UK... I

would say there might even be a difference between who they are, as to who

they ought to be..."

Interview 5

Moreover, a general concern existed as to whether the Cabinet Office as the community leaders are sufficiently engaged with the broader elements of the health security agenda, due to the perceived narrowing of focus towards topical concerns around the UK leaving the European Union, securitisation and the national counter-terrorism agenda:

"In terms of understanding the needs for an overarching framework, then Cabinet Office is currently the home for that coordination, but whether it yet fully sees its role as bringing together and coordinating, that action is another question. At the moment, it is very much a functional role that it has. So, responding to threats, anticipating threats, and mobilizing response to it, without necessarily seeing this for the UK to potentially engage with more systematically."

Interview 7

Although several health security leadership groups were reported to exist across government, little consensus existed about when or where they met, what outputs were envisaged, or who was consistently represented (e-Appendix 2). Public Health England (PHE) was recognized to convene several of these groups, including the Human Animal Infections and Risk Surveillance (HAIRS) group ${ }^{40}$, and the Global Health Security Program Board ${ }^{4}$. The Global Health Security Program Board was reported to have played an essential role historically in aligning UK health security strategy and activities, under the 'Health is Global' policy ${ }^{42}$, which finished in 2015 , and had ensured that a breadth of community members had a voice around the table. However, participants reported that since 2015, this forum had become narrower in its focus and had reduced to a few key government players at Department of Health, Department for International Development and Public Health England. Why this had occurred was not clear. Besides these traditional actors in domestic and global health, a diverse set of community leaders were reported to have emerged as the health security space expands. Influencers in this space were reported to now range from senior academics, to board members of charities working on global health issues, and civil society advocates with significant social media platforms. Despite this growing diversity, a central leadership and governance framework to engage and coordinate these efforts was noted to be absent from UK global health architecture. As such, participants considered the responsibility for strategy development and implementation, without clear and authoritative leadership, to be at risk of falling between stakeholders, and of the UK global health security nexus being vulnerable to co-opting into other debates and agendas. As one participant explained: 
"It is a contentious area and I think leaders have a huge amount of

responsibility here...I think there is an important leadership role in messaging.

I think it needs good communications...one agenda that works across all

(sector) leaders."

Interview 10

Recognizing this failure, a call for stronger leadership and governance capacity to manage the communication, architecture and programme coordination of the space was conveyed by all participants.

Health Security in UK Policy

No overarching strategic framework or policy, for either the health security agenda or wider UK global health strategy, was identified by participants. Concerns were raised that the policy vacuum left by the internationally heralded UK 'Health is Global' strategy ${ }^{42}$ has left the UK without strategic direction and leadership essential for activity accountability and delivery, around not only health security, but the wider global health agenda. As several key participants highlighted:

"We (UK) don't have a coordinated strategy that says this is what we are going to do. These are the minimum standards for consideration for any programmes we are going to do. These are the areas we are going to work in. We've just simply not got that."

Interview 4

"So, you need to get the UK bit right. We would really need as a country, as we discussed, a common policy that can be translated into everybody's language so that we are all behind it." Interview 3

The National Security Strategy ${ }^{2}$ was referenced as the principal contemporary document to set out transnational threats to health as a national priority, but operationalizing this mandate was subject to institutional interpretation and priority. Public Health England's 'Global Health Strategy' 43 , and the Department for International Development's latest ODA strategy ${ }^{1}$ were felt to go some way in making the vision of these UK institutions more transparent. However, much of the available documentation focused at a top tier level of institutional objectives and therefore were lacking in an accessible community narrative, programmatic detail or measurable outcomes. Therefore, with the overarching 'One HMG Overseas'strategy ${ }^{44}$ asserting a closer relationship between UK stakeholders, a need for planning models and a strategy were considered timely in order to create conditions for cross government cooperation. As one participant noted that:

"Yes, there are commonalities, but I don't think they are articulated as common

objectives."

Interview 8

Fundamental political and normative differences amongst participants were bridged by the need for an agreed strategy to both support and justify decisions around the expanding domestic and global health security agenda. Diverse suggestions included; a broad strategic thinking group, development of a national plan, a mapping of the declared 'UK contribution' to GHS, a review of the UK health capacity as a public good, a minister accountable for global health and a broader series of coordinated process' to mitigate risk. However, all participants agreed with the sentiments of one who proposed that:

"It is much more useful to look at the global health approach of which security is a part... These all need to be captured in a strategic document that brings it all together and then we individually as different departments with an interest will have a responsibility to cascade from there."

Interview 6

Theme 3. The role of global health security in wider UK health diplomacy.

The UK was considered by all participants to be a key figure in the wider global health security domain. Both in terms of its commitment to the $0.7 \%$ GNI goal for ODA, and as a key member and contributor to multilateral organizations including the G7, Munich Security Council ${ }^{45}$ and United Nations ${ }^{46}$. However, several participants reported concern that a lack of an agreed national strategy for global health security as it relates to wider policy and practice both i) threatens to undermine the UK's reputation as a leader in the field $(n=8)$, and, ii) risks leaving the UK with a poverty of negotiating power at high-level health and foreign policy platforms $(n=5)$. Although many participants were hesitant to comment on the potential impact of the UK's decision to leave the European Union, a unanimous agreement existed that the coming years would be ones of concerted effort to ensure that the global health security agenda remained centre stage for the UK and its position as a global influencer. With one participant noting that,

"I think there is a need to think more strategically not only about how we

build up the UK's capability, both for our own use but also how we become

Page 6/11 
Consensus existed of the need to align behind a coordinated UK contribution to the evolving health security agenda globally ( $n=12$ ). A need to mitigate against the risks created by contemporary political pressure to balance domestic interests with overseas spending was stated by several participants ( $\mathrm{n}=5$ ). Getting this right was considered as vital in ensuring the UK's ongoing global position as a leader in biological sciences and in health diplomacy efforts.

The UK governments' increasingly transparent move towards a position of 'enlightened self-interest' was considered by several participants ( $\mathrm{n}=6)$ an opportunity to move discussions away from the historical donor-recipient approach, in favour of a more mature conversation around partnering with countries to share technical health security expertise and build mutually beneficial capacity. Activities mentioned included the championing of transnational health security initiatives such as Global Health Security Agenda (GHSA) ${ }^{41}$, Antimicrobial Resistance (AMR) ${ }^{47}$ and the International Health Regulations (IHR) ${ }^{48}$ as part of the UKs wider global health commitments to international solidarity and stabilisation programmes. However, although considered a valuable tool in terms of developing UK 'soft power', the inflated health security agenda was felt by many participants $(n=7)$ to come with challenges for a harmonised UK One HMG approach. Particular reference was made to issues around duplication of activity $(n=9)$, the reliance on permissive political conditions and confusion regarding expressed motivations $(n=7)$. A model of coordinated UK response for global health security was considered essential, not only for the development of health security governance, but as an effective tool for synergising UK's diplomatic policies with the wider global health agenda.

\section{Discussion}

COVID-19 has fundamentally exposed the lacunae in the UK global health security architecture ${ }^{3,23,24}$. The findings from this research speak to a number of areas and organisations: One HMG, especially the new Foreign Commonwealth and Development Office (FCDO) and Humanitarian Stablisation and Operations Team (HSOT), the British Military (77 Brigade, Defence Medical Services, Defence Intelligence Services), and new arms lengths bodies such as National Institute for Health Protection (NIHP) ${ }^{49}$. The findings are especially germane for the Integrated Review and the future of UK's approach to global health security, including the pillars of public and global health intelligence, protection, mitigation and response.

The overall findings of this study revealed that UK global health leaders and decision-makers considered the contemporary architecture of governance around the expanding UK health security community to be of insufficient capacity. Despite increased political priority and investment, e.g. the Conflict Stability and Security Fund (CSSF) increased budget from $£ 683$ million in 2014/5 (under previous title of the Conflict Pool) to $£ 1.127$ billion in $2016 / 17$ with major diversification of the portfolio ${ }^{50-51}$, the concept of global health security remained contested in Whitehall and among wider UK global health community. This is not unique to the UK. There is limited global consensus around the normative principles, values systems, and rationale that underpin contemporary health security policy and practice $22,23,52-58$.

Furthermore, the absence of clear architecture and guiding policy for what constitutes health security has created a confused and opaque funding structure for decision-makers (e-Appendix 2). A diversification of funding, available to a broad array of institutions, for health security activities has created additional institutional competition and a lack of incentive for UK actors to collaborate operationally. In this post Ebola and pre-COVID era, despite wider skeptism for a more coherent approach, this study discovered an authentic desire amongst the most senior operational leaders within the UK health security architecture for the development of stronger collaborative relationships, governance and leadership. The ongoing UK response to COVID-19 pandemic has re-enforced both the absence of, and need, for clear governance architectures and policies for health security ${ }^{3,23}$. The UK and international response to COVID-19 pandemic illuminate the contemporary validity of key thematic findings from this analysis ${ }^{3,59-61}$

Our first major finding is that consensus needs to be built around a compelling public narrative for the UK contribution to global health security. Narratives are the foundation of governance; of how societies agree, plan and design systems to reflect their cultural values and principles ${ }^{58,62-64}$. No consensus exists as to what UK health security decision makers consider to constitute health security. Neither is there clarity on the topography of how health, development and security communities operate in this space nor the UK governance architecture of stakeholders' active in this expanding community. Consequently, unclear organizational mandates and a lack of a cohesive national health security narrative have left UK global health initiatives vulnerable to failing the public good test i.e. using resources for overt securitisation projects that have little or no impact on health. Decision makers therefore advocated for the development of an agreed public position for global health security. This position should align UK domestic and international policy commitments to a strategic set of shared behaviours and values for organizations representing the UK in this space. Building on lessons learnt, this approach would aim to integrate ODA for health security activities and improve alignment for cross sector communication. The development of a compelling and consistent narrative for the UK's contribution to global health security is timely to establish its position within the new architecture of the FCDO.

Secondly, an effective architecture needs to be built for the coordination of stakeholders' active in the UK health security community. Factors impacting health security were understood to be cross cutting and to require the collective agreement of decision-makers to improve health outcomes. Yet, in practice, there has been a lack of incentive to collaborate due to limiting organisational mandates, driven by institutional growth and narrow funding pathways, as well as an established culture of stove pipe working within the UK health security community ${ }^{33}$. The impact of this fragmented health security architecture has detracted from partnerships with key overseas strategic countries. These interactions were characterized as an overburdening of national health ministry partners, with 'a bewildering array of agencies from which to elicit support... and donors whose interests, activities and processes sometimes overlap, but often differ'. In creating the Joint Biosecurity Centre, the UK has taken the first tentative steps in recognizing this problem. However, health security remains deeply divided operationally and politically $3,6,22,23,52,54$. 
In response to this fragmentation in communication and a failure to engage non- traditional actors, participants proposed that the UK global health community could learn from the experience of other approaches, such as climate change and disaster risk reduction policy ${ }^{65,66}$. The success of these communities was attributed to the combination of strong models of coordination and governance frameworks targeted at strengthening high level policy decisions. In line with the COVID-19 experience of ambiguity in the UKs Four Nations approach to response, a need for the use of combined research, technology and shared communication platforms to reconnect departments, and devolved administrations, in their attempt to manage and mitigate health security challenges. Consequently, the establishment of a transparent architecture to govern an increasing array of UK health security activity will be necessary both to strengthen wider policy and prioritisation, and to secure the future operational synergy of UK inter-sectoral initiatives (e-Appendix 3 and 4 ).

Finally, forums for cross sector engagement and regulation must be created in order to find innovative solutions to challenges that extend beyond the boundaries of a single organisation or community. Although several small boards and committees were reported to meet in government to debate health security priorities, activities and funding, a limited breadth of stakeholder participation was reported to be creating group think' (e-Appendix 2). To a significant degree this has been reflected in the UK's response to the COVID-19 pandemic ${ }^{3,22}$. It is recognised that central forums for health security knowledge exchange need to be created to mitigate against a reliance on institutional memory ${ }^{3,33}$. Transparent outputs that resonate with existing policy and resource priorities are the most valuable in developing strong arguments and accountability for resourcing around health security activities ${ }^{67-69}$.

Inter-sectoral forums and projects incentivise collaborative working as they not only attracted funding for institutions but create a system of accountability for the work carried out ${ }^{70-71}$. This could be additionally strengthened with open access platforms where clear community findings, programme resourcing, and outputs are disseminated, are needed. An investigation into the use of innovative messaging techniques such as story mapping, publicly accessible dashboards, and technical platforms including central hubs and websites would ensure the pragmatic translation of policy into practice ${ }^{64}$. A clear statement of intent following the current Integrated Review, would allow for the UK to make a stronger and more sustainable contribution to wider health security knowledge and governance networks ${ }^{72-73}$.

\section{Conclusion}

The strategic priorities identified as a result of this study situated between the two major Ebola epidemics and the COVID-19 pandemic speak to the need for a new radical approach to UK's global health security agenda. This will require considered and integrated policy-making that not only takes into account lessons learnt but also looks forward to a wider strategic vision around health security ${ }^{48}$ (Figure 2 on appendix).

\section{Figure 2 on appendix. Benefits and Impacts of recommended strategic priorities}

The impact of security, as it relates to the health of individuals, health providers, and their communities, is now central to global health debate. A recent broadening of the UK National Security Strategy to include threats to health has raised the profile of the global health security agenda, in recognition of its influence on contemporary UK diplomatic efforts. Yet findings suggest that UK global health leaders and decision makers consider the contemporary architecture of governance around the expanding UK health security community to be insufficient. The concept of effective community positioning around health security activity, architecture, and regulation, remains understood differently by UK leaders and decision makers.

With increased scrutiny over the future of ODA and UK diplomacy post departure from the European Union, a lack of coordination and clear leadership around a national strategy for health security activity threatens to undermine the effectiveness of the UK's 'One HMG Overseas' strategy. This study draws out three strategic priorities to strengthen the governance capacity of the UK health security community: Firstly, consensus needs to be built around a compelling public narrative for the UK contribution to global health security; secondly, an effective model of coordination needs to be built for stakeholders, active in the UK health security community; thirdly, forums for cross- sector engagement and regulation must be created in order to find innovative solutions to these problems that extend beyond the boundaries of a single organisation or community.

\section{Limitations}

Consideration was given to sample bias and where possible selection was and addressed by the clear definition and recruitment of study participants as experts with specialist knowledge from a broad range of professional backgrounds and experiences. A gender bias in the sample exists towards male participants due to both lack of women in these roles but also access to them. In addition to the methodological limitations, during the research process, several terrorist incidents occurred in central London and a general election was called by the British Prime Minister. These events were unaccounted for in planning and therefore led to difficulty accessing civil servants during the six-week period of Purdah leading up to the election. As such informal comment and conversation were engaged in with the UK Department of Health and Social Care (DHSC) but completion of formal interviews was not possible. Furthermore, the longer-term implications on global health security activity following the recent COVID-19 outbreak are not yet known.

\section{Declarations}

Competing interests: The author declares that they have no competing interests

Author Contributions: EM conceived, designed, collected, managed and analysed the data.

Ethics approval and consent to participate: A low risk ethics application was approved by the Kings College London Ethics Review and the research conformed to the principles embodied in the Declaration of Helsinki. Written and verbal consent was given by all study participants

Consent for publication: Written consent forms were signed by all participants for the publication of data collected. 
Availability of data and materials: The datasets used and/or analysed during the current study are available from the corresponding author on reasonable request.

Funding: No funded was sought for this work

Acknowledgments: The author (EM) would like to take this opportunity to acknowledge those who made this piece of work possible. To all those who agreed to give their valuable time to participate and share their invaluable experience and insights. To Professor Richard Sullivan; for his time, advice and expertise.

\section{References}

1. UK Treasury and Department for International Development. UK aid: tackling global challenges in the national interest. 2014. Available at https://www.gov.uk/government/uploads/system/uploads/attachment_data/file/478834/ODA_strategy_final_web_0905.pdf. Last accessed 3rd July 2020.

2. UK Government. National Security Strategy and Defence Review 2015. Available at https://www.gov.uk/government/uploads/system/uploads/attachment_data/file/478933/52309_Cm_9161_NSS_SD_Review_web_only.pdf. Last accessed August 12th, 2020

3. Freedman L. Strategy for a Pandemic: The UK and COVID-19. The International Institute for Strategic Studies, 11 May 2020 . Available at https://www.iiss.org/blogs/ survival-blog/2020/05/the-uk-and-covid-19. Last accessed 21 August 2020.

4. World Health Organization. The world health report 2007: a safer future: global public health security in the 21st century. 2007. Available at http://www.who.int/whr/2007/en. Last accessed 24th August 2020.

5. Fidler DP. Influenza virus samples, international law, and global health diplomacy. Emerging Infectious Diseases. 2008.14(1): 88-94.

6. Heymann DL, Chen L, Takemi K, Fidler DP, Tappero JW, Thomas MJ, Kenyon TA, Frieden TR, Yach D, Nishtar S, Kalache A. Global health security: the wider lessons from the West African Ebola virus disease The Lancet. 2015 May 15; 385(9980):1884-901.

7. United National Development Programme. Human Development Report. 1994. Available at http://hdr.undp.org/sites/default/files/reports/255/hdr_1994_en_complete_nostats.pdf Last accessed 4th August 2017.

8. United Nations. 'Human Security Now' Final Report. 2003. Available at http://www.un.org/humansecurity/sites/www.un.org.humansecurity/files/chs_final_report_-_english.pdf . Last accessed 5th August 2017.

9. Meddings DR. Personal views: Human security: a prerequisite for health. BMJ: British Medical Journal. 2001 Jun $23 ; 322$ (7301):1553.

10. Paris R. Human security: Paradigm shift or hot air? International security. 2001; 26 (2):87-102.

11. Fidler DP. Public health and national security in the global age: infectious diseases, bioterrorism, and realpolitik. Geo. Wash. Int'I L. Rev. $2003 ; 35$ : 787.

12. UK Department for International Development (DFID). Why we need to work more effectively in fragile states. 2005. Available at https://www.jica.go.jp/cdstudy/library/pdf/20071101_11.pdf . Last accessed 6 ${ }^{\text {th }}$ August 2017.

13. Hosseini-Divkolaye NS, Radfar MH, Seighali F, Burkle FM. When health diplomacy serves foreign policy: use of soft power to quell conflict and crises. Disaster medicine and public health preparedness. 2016 Oct (1):1-4.

14. Hotez PJ, Thompson TG. Waging peace through neglected tropical disease control: a US foreign policy for the bottom billion. PLoS Negl Trop Dis. 2009 Jan 27;3 (1): e346.

15. Katz R, Singer DA. Health and security in foreign policy. Bulletin of the World Health Organization. 2007 Mar;85(3):233-4

16. Frenk J, Gómez-Dantés O, Moon S. From sovereignty to solidarity: a renewed concept of global health for an era of complex interdependence. The Lancet. 2014 Jan 4;383(9911):94-7.

17. Feldbaum H, Michaud J. Health diplomacy and the enduring relevance of foreign policy interests. PLoS Med. 2010 Apr 20;7(4): e1000226.

18. World Bank. World development report 2011: conflict, security, and World Bank; 2011.

19. Benton B, Handuleh J, Harris K, Maruthappu M, Patel P, Godman B, Finlayson AE. Health in fragile states. Medicine, Conflict and Survival. 2014 Jan 2;30(1):19-27.

20. Haar RJ, Rubenstein LS. Health in fragile and post-conflict states: a review of current understanding and challenges ahead. Medicine, Conflict and Survival. 2012 Dec 1;28(4):289-316.

21. Walsh PF. Improving 'Five Eyes' health security intelligence capabilities: leadership and governance challenges. Intell Natl Security. DOI: 10.1080/02684527. 2020.1750156.

22. Sullivan etc.

23. Nolte, W. Lessons from the corona virus: a response to the special issue on health security intelligence,Intelligence and National Security,Sept 2020. DOI: 1080/02684527.2020.1812240

24. Press Release: https://www.gov.uk/government/news/prime-minister-announces-merger-of-department-for-international-development-and-foreign-office. Available athttps://www.gov.uk/government/organisations/department-for-international-development. Last accessed 6th August 2020.

25. Institute for Government. The Joint Biosecurity Centre. Available at https://www.instituteforgovernment.org.uk/explainers/joint-biosecurity-centre. Last accessed 6th Sept 2020

26. The Guardian. Concerns raised over government attempts to redefine overseas aid. Available at https://www.theguardian.com/globaldevelopment/2016/jan/25/uk-government-lobbying-changes-overseas-aid-definition-international-development-budget . Last accessed 7th August 2020.

Page 9/11 
27. UK Government: Biological Security Strategy. Available at https://www.gov.uk/government/publications/biological-security-strategy. Last accessed $28^{\text {th }}$ August 2020.

28. All Party Parliamentary Group on Biosecurity and National Security. Call for Evidence. Available at https://committees.parliament.uk/call-forevidence/150/biosecurity-and-national-security/. Last accessed $10^{\text {th }}$ September 2020.

29. UK Government. Government creates new national institute for health protection. Available at https://www.gov.uk/government/news/government-createsnew-national-institute-for-health-protection. Last accessed 4th September 2020.

30. Horton R, Das P. Global health security now. The Lancet. 2015 May 9;385(9980):1805-6.

31. Kickbusch I. Global health diplomacy: How foreign policy can influence health. BMJ: British Medical Journal. 2011 Jun 10;342.

32. Chan M. Director General Address to the WHO high level conference on global health security. 2016. Available at http://www.who.int/dg/speeches/2016/global-health-security/en . Last accessed 4th July 2019.

33. Media Coverage of Exercise Cygnus findings. The Guardian. Available at https://www.theguardian.com/world/2020/may/07/revealed-the-secret-reportthat-gave-ministers-warning-of-care-home-coronavirus-crisis. Last Accessed 7th September 2020; and The Telegraph. Available at https://www.telegraph.co.uk/news/2020/03/28/exercise-cygnus-uncovered-pandemic-warnings-buried-government/. Last accessed 7th September 2020.

34. Creswell JW. Research design: Qualitative, quantitative, and mixed methods approaches. Sage publications; 2013.

35. Guest G, Namey EE, Mitchell ML. Collecting qualitative data: A field manual for applied research. Sage; 2012.

36. Boyce C, Neale P. Conducting in-depth interviews: A guide for designing and conducting in-depth interviews for evaluation input. Pathfinder International. 2006.

37. Mason M. Sample size and saturation in PhD studies using qualitative interviews. In Forum, qualitative Sozialforschung/Forum: qualitative social research. 2010: (11) 3

38. Bazeley, P. and Jackson, K. Qualitative Data Analysis with NVivo. 2013. Los Angeles, CA, SAGE Publications.

39. Saldana, J. The Coding Manual for Qualitative Researchers. 2013. Los Angeles, CA, Sage Publications, Inc.

40. Public Health England. Human Animal Infections and Risk Surveillance Group (HAIRS). Available at https://www.gov.uk/government/collections/humananimal-infections-and-risk-surveillance-group-hairs. Last accessed 17th July 2020.

41. Global Health Security Initiative. GHSA Index. Available at http://www.ghsi.ca/english/index.asp Last accessed 16 th August 2020.

42. Donaldson L, Banatvala N. Health is global: proposals for a UK Government-wide strategy. The Lancet. 2007 Mar 16;369(9564):857-61

43. Public Health England. Global Health Strategy 2014-19. Available at https://www.gov.uk/government/uploads/system/uploads/attachment_data/file/354156/Global_Health_Strategy_final_version_for_publication_12_09_1_ . Last accessed 16th January 2017.

44. UK National Audit Office. One HMG Overseas: A briefing for the House of Commons Foreign Affairs Committee. March 2015. Available at https://www.nao.org.uk/wp-content/uploads/2015/03/One-HMG-Overseas.pdf. Last accessed 10th August 2017.

45. Munich Security Conference 2017. Panel Discussion "Health Security: Small Bugs, Big Bombs". 18 February 2017. Video available at https://www.securityconference.de/en/media-library/munich-security-conference-2017/video/panel-discussion-health-security-small-bugs-bigbombs/filter/video. Last accessed 6th August 2019.

46. The New Statesman. Can the UK save the United Nations from Donald Trump's cuts? 2017. Available at http://www.newstatesman.com/politics/staggers/2017/06/can-uk-save-united-nations-donald-trumps-cuts Last accessed 12 th August 2020.

47. UK Government. Antimicrobial Resistance, information and resources. Available at https://www.gov.uk/government/collections/antimicrobial-resistanceamr-information-and-resources. Last accessed 13th August 2020.

48. International Health Regulations. 2015. Available at http://apps.who.int/iris/bitstream/10665/246107/1/9789241580496-eng.pdf?ua=1. Last accessed on 6th August 2020.

49. UK Government. Government creates new national institute for health protection. Available at https://www.gov.uk/government/news/government-createsnew-national-institute-for-health-protection. Last accessed on 7th September 2020.

50. UK Parliament. Conflict Security and Stability Enquiry launched. Available at https://www.parliament.uk/business/committees/committees-a-z/jointselect/national-security-strategy/news-parliament-2015/cssf-launch-16-17. Last accessed 13th August 2020.

51. McVeigh K. The Guardian "Secrecy around the one billion aid and security fund raises significant concern says MPs. $7^{\text {th }}$ Feb 2017. Available at https://www.theguardian.com/global-development/2017/feb/07/secrecy-around-1bn-aid-and-security-fund-raises-significant-concern-say-mps. Last accessed 5th May 2020.

52. Rushton S. Global health security: security for whom? Security from what? Political Studies. 2011 Dec; 59(4):779-96.

53. Mclnnes C. The many meanings of health security. The Routledge Handbook of Global Health Security. 2015:7-17.

54. Kanji L. Hidden Dangers: The implications of the Global Health Security Agenda. $15^{\text {th }}$ April 2016. Available at http://hir.harvard.edu/article/?a=13091. Last accessed $23^{\text {rd }}$ July 2018.

55. Gordon S. Health, stabilization and securitization: towards understanding the drivers of the military role in health interventions. Medicine, conflict and survival. 2011 Jan 1; 27(1):43-66.

56. Fidler D. Architecture amidst anarchy: global health's quest for governance. Global Health Governance. 2007.

57. World Health Organisation. Health security: is the world better prepared? Available at http://www.who.int/publications/10-year-review/health-security/en. Last accessed 8th August 2020.

Page $10 / 11$ 
58. Alkire S, Chen L. Global health and moral values. The Lancet. 2004 Sep 18;364(9439):1069

59. Ladner D, Katsumasa H and Kyuri K. The Republic of Korea's First 70 Days of Responding to the COVID-19 Outbreak. Global Delivery Initiative, Case Study, 13 April 2020. See www.globaldeliveryinitiative.org/sites/ default/files/case-studies/case_study_of_korea_response_to_covid19.pdf (last checked 11 June 2020).

60. Gudbjartsson DF, Helgason A, Jonsson H, et al. Spread of SARS-CoV-2 in the Icelandic Population. New Engl J Med. DOI: 10.1056/NEJMoa2006100.

61. Spahn J. How Germany Contained the Coronavirus. World Economic Forum. See https://www.weforum. org/agenda/2020/05/how-germany-containedthe-coro- navirus/ (last checked 11 June 2020).

62. Ney S. Making sense of the global health crisis: Policy narratives, conflict, and global health governance. Journal of health politics, policy and law. 2012 Apr 1;37(2):253-95.

63. Petersen A. Risk, governance and the new public health. Foucault, health and medicine. 1997:189-206.

64. Kickbusch I. Governing the Global Health Security Domain. Global Health Programme Working Paper, (12). 2016.

65. Leaning J, Guha-Sapir D. Natural disasters, armed conflict, and public health. New England journal of medicine. 2013 Nov 7;369(19):1836-42

66. United Nations. Sendai Framework for disaster risk reduction. 2015. Available at https://www.unisdr.org/files/43291_sendaiframeworkfordrren.pdf. Last accessed on 2nd August 2017

67. Labonté R, Gagnon ML. Framing health and foreign policy: lessons for global health diplomacy. Globalization and Health. 2010 Aug 22;6(1):14

68. Shiffman J, Smith S. Generation of political priority for global health initiatives: a framework and case study of maternal mortality. The lancet. 2007 Oct 19;370(9595):1370-9.

69. Shiffman J. A social explanation for the rise and fall of global health issues. Bulletin of the World Health Organization. 2009 Aug;87(8):608-13.

70. Martin DK, Giacomini M, Singer PA. Fairness, accountability for reasonableness, and the views of priority setting decision-makers. Health policy. 2002 Sep 30;61(3):279-90.

71. Goetghebeur M, Castro-Jaramillo H, Baltussen R, Daniels N. The art of priority setting. The Lancet. 2017 Jun 23;389(10087):2368-9.

72. Gostin LO, Mok EA. Grand challenges in global health governance. British medical bulletin. 2009 Jun 1;90 (1).

73. Frenk, J. and Moon, S. Governance challenges in global health. New England Journal of Medicine, 2013.368(10), 936-942

\section{Supplementary Files}

This is a list of supplementary files associated with this preprint. Click to download.

- GHAppendicesTablesFigures.docx 